\title{
Visualization of the distribution of surface-active block copolymers in PDMS-based coatings
}

Noguer, A. Camós; Latipov, R. ; Madsen, F. B.; Daugaard, A. E. ; Hvilsted, S.; Olsen, S. M.; Kiil, S.

Published in:

Progress in Organic Coatings

Link to article, DOI:

10.1016/j.porgcoat.2018.03.011

Publication date:

2018

Document Version

Peer reviewed version

Link back to DTU Orbit

Citation (APA):

Noguer, A. C., Latipov, R., Madsen, F. B., Daugaard, A. E., Hvilsted, S., Olsen, S. M., \& Kiil, S. (2018).

Visualization of the distribution of surface-active block copolymers in PDMS-based coatings. Progress in Organic Coatings, 120, 179-189. https://doi.org/10.1016/j.porgcoat.2018.03.011

\section{General rights}

Copyright and moral rights for the publications made accessible in the public portal are retained by the authors and/or other copyright owners and it is a condition of accessing publications that users recognise and abide by the legal requirements associated with these rights.

- Users may download and print one copy of any publication from the public portal for the purpose of private study or research.

- You may not further distribute the material or use it for any profit-making activity or commercial gain

- You may freely distribute the URL identifying the publication in the public portal 


\title{
Visualization of the distribution of surface-active
}

\section{block copolymers in PDMS-based coatings}

A. Camós Noguer ${ }^{\mathrm{a}, \mathrm{b}}$ R. Latipov ${ }^{\mathrm{b}}$ F.B. Madsen ${ }^{\mathrm{a}}$ A.E. Daugaard ${ }^{\mathrm{a}}$ S. Hvilsted ${ }^{\mathrm{a}}$ S.M. Olsen ${ }^{\mathrm{b}}$ and S. Kiil ${ }^{*, a}$

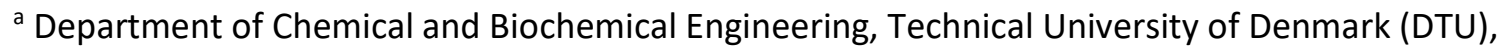
Building 229, 2800 Kgs. Lyngby, Denmark

${ }^{b}$ Department of Fouling Release Systems, Hempel A/S, Lundtoftegårdsvej 91, 2800 Kgs. Lyngby, Denmark

*Corresponding author, e-mail address: sk@kt.dtu.dk, telephone: +45 45252827 (Søren Kiil)

\begin{abstract}
Poly(dimethylsiloxane) (PDMS) has been widely employed in the area of fouling-release coatings and other fields due to its unique combination of properties including low elastic modulus and low glass transition temperature. The drawback of PDMS in some applications is its hydrophobic surface, which results in non-specific protein adsorption and wettability issues. Poly(ethylene glycol)-based surface-active block copolymers and surfactants have been added to PDMS coatings and films to impart biofouling resistance and hydrophilicity to the PDMS surface with successful results. Information regarding the distribution and release of these block copolymers from PDMS-based coatings has been previously reported. However, the distribution and behaviour of these compounds in the bulk of the PDMS coating are not fully understood.
\end{abstract}

A novel fluorescent-labelled triblock PEG-b-PDMS-b-PEG copolymer was synthesized and added to a PDMS coating for visualization purposes. The surface-activity and biofouling resistance of the synthesized copolymer was confirmed by water contact angle measurements and seawater immersion experiments. Confocal laser scanning microscopy (CLSM) images showed that the triblock 
copolymer aggregates in spherical domains within the PDMS coating film. The size of these domains vary between 1 and $7 \mu \mathrm{m}$, with larger domains being present on the bulk of the film and smaller closer to the surface. The diffusion of the copolymer could be observed over time, with copolymer molecules diffusing from the bulk to the surfaces of the PDMS film. Finally, an overview of the possibilities provided by the presented methodology in the field of fouling-release coatings is discussed.

\section{Introduction}

Polydimethylsiloxane (PDMS) is an extensively used polymer in a range of areas such as dielectric elastomers, microfluidic systems, microreactors, membranes, adhesives, coatings and biomedical devices [1-3]. In the field of marine biofouling, PDMS is the most widely employed binder for fouling-release coatings (FRC), which have become a solid alternative to biocidal antifouling coatings after the ban of tributyltin (TBT) in the early 2000s [4]. The widespread use of PDMS in such different areas is due to its unique combination of properties, including thermal and chemical stability, low elastic modulus, low glass transition temperature, smooth surface and low cost, among others [2,5-8]. However, the hydrophobic nature of PDMS has been a drawback in areas such as microfluidics, biomedicine and marine coatings due to adsorption of proteins and cells on its surface, as well as wettability issues $[2,3,9,10]$.

\subsection{Functionalization of PDMS surfaces}

To change the surface properties of PDMS and make it hydrophilic, different methods have been employed such as oxygen plasma exposure, surface adsorption of surfactants and chemical modification (grafting) $[2,9,10]$. These methods are generally too expensive and/or 
complicated and therefore not suitable for some of the aforementioned applications. In addition, the PDMS surface tends to recover its hydrophobicity over time [11].

A different method to modify the surface properties of PDMS coatings and films is gaining popularity, namely the addition of small amounts of surface-active copolymers and amphiphiles to uncured PDMS mixtures $[2,9,12,13]$. The idea of adding small amounts of copolymers to change the surface properties of polymeric materials was first introduced by Zisman and co-workers in 1964 [14]. Upon curing, copolymer molecules migrate to the PDMS surface and impart hydrophilicity to the surface [12]. Several patents [15-21] and articles [22-26] have been published in the field of fouling-release coatings describing the addition of various amphiphilic copolymers (usually known as "silicone oils") with the objective of modifying the hydrophobic surface properties of PDMS coatings. Poly(ethylene glycol) (PEG) has been one of the most widely employed polymers for that purpose. For example, PDMS-PEG block copolymers have been used to reduce the amount of biofouling and barnacle adhesion strength on PDMS-based fouling-release coatings [27]. Likewise, these have been used for other purposes such as to improve the wettability of PDMS surfaces for microelectromechanical systems [28] and for capillary-driven systems in the biomedical field [29]. Similarly, other PEG-based block copolymers have been added to modify the surface properties of PDMS to improve its wettability $[2,10]$ or to supress nonspecific protein adsorption $[9,30]$.

Despite the wide use of this approach, there is a lack of knowledge regarding the distribution, mobility, behaviour and interaction of block copolymer additives in polymeric hosts. Most of the work has been focused on the final properties of the surface of these materials, studied either by direct (e.g. X-ray photoelectron spectroscopy (XPS)) or indirect 
methods (e.g. contact angle measurements and atomic force microscopy (AFM)) $[9,12]$. Nonetheless, there is a lack of understanding of the processes occurring in the bulk of the film. Due to the importance of these copolymers on the final properties of the PDMS-based films, new methods are aimed at better understanding the distribution and behaviour of the copolymers hosted in the bulk of these materials. To that purpose, different methods have been presented in our previous work, regarding the diffusion [31], release [32] and degradation [33] of PDMS-PEG-based amphiphilic copolymers in PDMS fouling-release coatings. However, none of the methodologies developed allowed visualization of the distribution of the amphiphilic copolymer in the bulk of the PDMS coating.

\subsection{Fluorescent-based visualization techniques}

The development of fluorescence-based techniques has proven to be a powerful tool to study and visualize some of the abovementioned phenomena. For example, Kósa et al. [34] used fluorescent probes to study the morphology and the diffusion processes taking place within interpenetrating polymer networks. Martin and Webber [35] studied the behaviour and micellization of amphiphilic block copolymers labelled with different probes in solution, while Konash et al. [36] studied the distribution and interaction of enzymes incorporated into a polymer matrix. Finally, Cui et al. [37] recently used perylenediimide to label a silicone oil added to a supramolecular gel matrix, where the secretion of the silicone oil was exploited for self-healing purposes.

\subsection{Aim and scope}

This paper presents a method for visualizing the distribution of surface-active amphiphilic copolymers added to PDMS films and coatings, inspired by the work of Madsen et al. [38,39], where 4-methylumbelliferone, a fluorescent moiety, was used to label a crosslinker 
for PDMS. The synthetic pathway was chosen because it allowed the coupling of three different techniques (i.e. Piers-Rubinsztajn reaction, hydrosilylation and click chemistry) in mild conditions, which produced a relatively high yield of the desired product with an acceptable dispersity (D).

Here, a novel copolymer is synthesized for analytical purposes. A PEG-b-PDMS-b-PEG triblock copolymer is labelled with 4-methylumbelliferone, added to an uncured PDMS mixture and applied as a free film. Upon curing, the properties of the coating films are analysed and compared to a coating where the labelled copolymer was substituted by a commercial copolymer of similar characteristics. The similarities and divergences between the commercial and synthesized copolymer are discussed and compared to the properties of the coatings. Finally, the distribution and migration of the labelled triblock copolymer within the coating film are studied by confocal laser scanning microscopy (CLSM), allowing the visualization of the fluorescent-labelled molecules at different depths inside the bulk of the film over time.

\section{Experimental}

\subsection{Materials}

3-choloropropylmethyldimethoxysilane, hydride-terminated dimethylsiloxane (DMS-H11, $\mathrm{M}_{\mathrm{w}} \sim 1500 \mathrm{~g} / \mathrm{mol}$ determined by ${ }^{1} \mathrm{H}-\mathrm{NMR}$ ) and platinum-divinyl tetramethyldisiloxane (Karstedt's catalyst), with 2.1-2.4\% Pt in xylene, were purchased from Gelest Inc. Mono-allylterminated poly(ethylene glycol), (PolyglykolA500, $\mathrm{M}_{\mathrm{w}} \sim 500 \mathrm{~g} / \mathrm{mol}$ ), was purchased from Clariant. All other chemicals were acquired from Sigma-Aldrich and used as received unless otherwise stated. 
Silanol-terminated polydimethylsiloxane (4000 cSt) was obtained from Dow Corning and a 16-functional pre-polymerized alkoxysilane crosslinker (Dynasylan 40) was received from Evonik Industries. Dibutyltin dilaurate was received from TIB chemicals.

4-methyl-7-(prop-2-yn-1-yloxy)-2H-chromen-2-one, an alkyne-terminated coumarin molecule, was produced using the method described by Madsen et al. [40] and will not be covered here.

All the glassware used was flame-dried prior to usage, and all the reactions were carried out under a nitrogen atmosphere.

\subsection{Synthetic procedure}

The PEG-b-PDMS-b-PEG block copolymer labelled with 4-methyl-7-(prop-2-yn-1-yloxy)-2Hchromen-2-one was synthesized in a 4-step reaction, which can be seen in Figure 1 and is described below. 


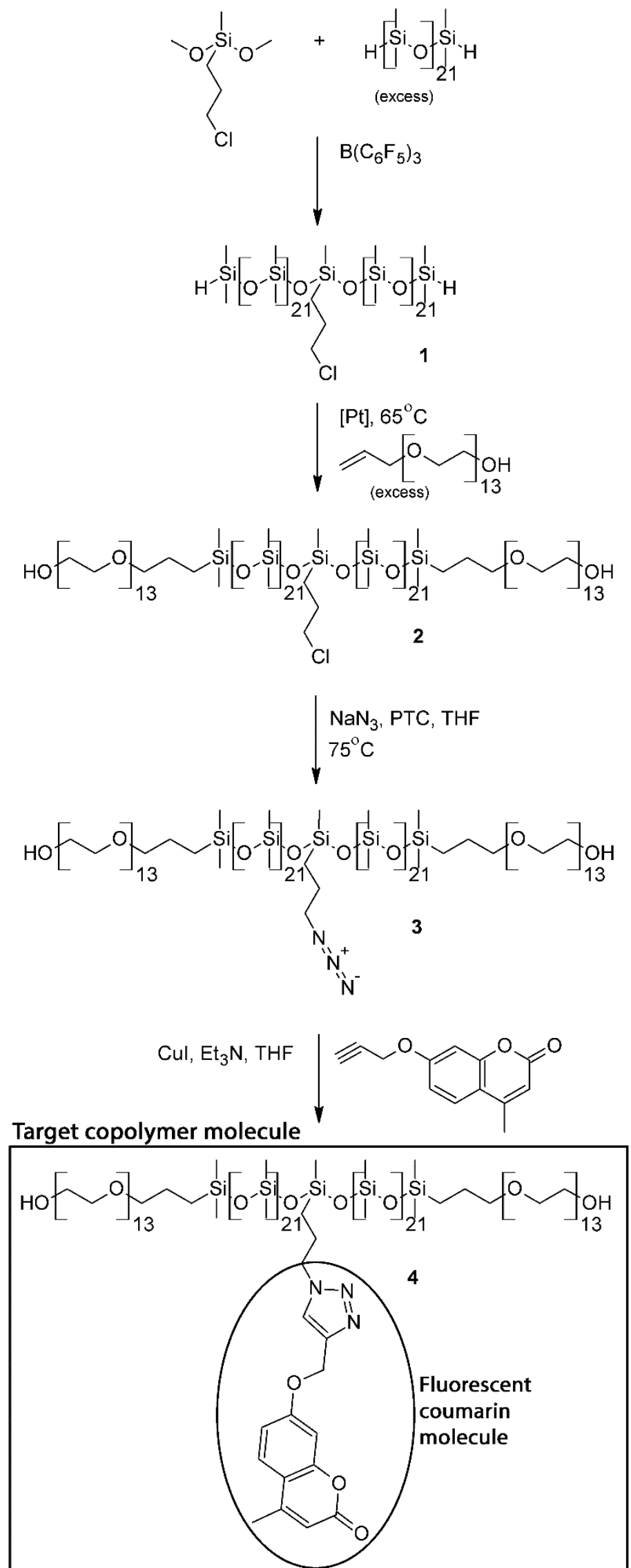

Figure 1. Synthesis route for the coumarin-labelled PEG-b-PDMS-b-PEG triblock copolymer. 


\subsubsection{Synthesis of PDMS(Cl) (1).}

3-choloropropylmethyldimethoxysilane $(1.00 \mathrm{~g}, 5.47 \mathrm{mmol})$ was dissolved in dry toluene $(16 \mathrm{~mL})$ in a three neck round-bottom flask. Hydride-terminated dimethylsiloxane $(17.24 \mathrm{~g}, 16.4 \mathrm{mmol})$ was added to the mixture and stirred for 10 minutes. Tris(pentafluorophenyl) borane in dry toluene $(0.7 \mathrm{~mL}, 0.002 \mathrm{M}, 0.03 \mathrm{~mol} \%)$ was added to the mixture. Methane gas immediately developed, and the reaction was kept under stirring for 5 minutes at RT, until no more methane formation could be observed. The product obtained was used without further purification.

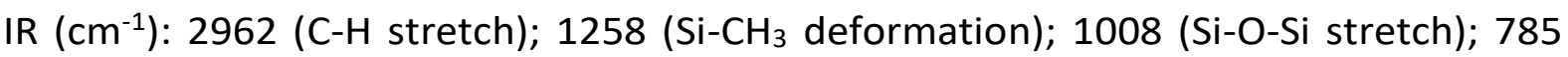
(Si-C stretch).

${ }^{1} \mathrm{H} N M R\left(\mathrm{CDCl}_{3}, \delta_{\mathrm{H}}, \mathrm{ppm}\right):-0.04$ to $0.09\left(\mathrm{~m}, 3 \mathrm{H}, \mathrm{Si}-\mathrm{CH}_{3}\right) ; 0.61\left(\mathrm{~m}, 2 \mathrm{H}, \mathrm{Si}-\mathrm{CH}_{2}-\mathrm{CH}_{2}-\mathrm{CH}_{2}-\right.$ $\mathrm{Cl}) ; 1.81\left(\mathrm{~m}, \mathrm{Si}-\mathrm{CH}_{2}-\mathrm{CH}_{2}-\mathrm{CH}_{2}-\mathrm{Cl}\right) ; 3.49\left(\mathrm{t}, \mathrm{J}^{3}=7.0 \mathrm{~Hz}, \mathrm{Si}--\mathrm{CH}_{2}-\mathrm{CH}_{2}-\mathrm{CH}_{2}-\mathrm{Cl}\right), 4.68(\mathrm{~m}, \mathrm{Si}-\mathrm{H})$. ${ }^{13} \mathrm{C} \mathrm{NMR}\left(\mathrm{CDCl}_{3}, \delta_{c}, \mathrm{ppm}\right): 0.4$ to $1.6\left(\mathrm{Si}-\mathrm{CH}_{3}\right) ; 15.0\left(\mathrm{Si}-\mathrm{CH}_{2}-\mathrm{CH}_{2}-\mathrm{CH}_{2}-\mathrm{Cl}\right) ; 26.7\left(\mathrm{Si}-\mathrm{CH}_{2}-\right.$ $\left.\mathrm{CH}_{2}-\mathrm{CH}_{2}-\mathrm{Cl}\right) ; 47.6\left(\mathrm{Si}-\mathrm{CH}_{2}-\mathrm{CH}_{2}-\mathrm{CH}_{2}-\mathrm{Cl}\right)$.

2.2.2 Synthesis of PEG-b-PDMS(Cl)-b-PEG (2). Mono-allyl-terminated PEG (14.24 g, $28.4 \mathrm{mmol}$ ) was added to the round-bottom flask containing the PDMS(Cl) (1). Platinum-divinyl tetramethyldisiloxane was dissolved in dry toluene and added to the mixture $(0.5 \mathrm{~mL}, 0.01 \mathrm{mM}, 150 \mathrm{ppm})$. The reaction mixture was heated to $65^{\circ} \mathrm{C}$ and allowed to react for 4 hours. At the end of the reaction, the excess of allyl-PEG (insoluble in toluene) was removed by decantation. The toluene was removed by rotatory evaporation under vacuum to obtain the product in the form of a clear brown oil (2). 
IR $\left(\mathrm{cm}^{-1}\right)$ : 3470 (-OH stretch); 2962 (C-H stretch); 2870 (aliphatic C-H stretch); 1258 (Si-CH 3 deformation); 1070 ( $\mathrm{CH}_{2}-\mathrm{O}-\mathrm{CH}_{2}$ stretch); 1008 (Si-O-Si stretch); 785 (Si-C stretch).

${ }^{1} \mathrm{H}$ NMR $\left(\mathrm{CDCl}_{3}, \delta_{\mathrm{H}}, \mathrm{ppm}\right):-0.02$ to $0.05\left(\mathrm{~m}, \mathrm{Si}-\mathrm{CH}_{3}\right) ; 0.51\left(\mathrm{~m}, \mathrm{Si}-\mathrm{CH}_{2}-\mathrm{CH}_{2}-\mathrm{CH}_{2}-\mathrm{O}\right) ; 0.62$ (m, $\left.2 \mathrm{H}, \mathrm{Si}-\mathrm{CH}_{2}-\mathrm{CH}_{2}-\mathrm{CH}_{2}-\mathrm{Cl}\right) ; 1.61$ (m, Si- $\left.\mathrm{CH}_{2}-\mathrm{CH}_{2}-\mathrm{CH}_{2}-\mathrm{O}\right) ; 1.81$ (m, Si- $\mathrm{CH}_{2}-\mathrm{CH}_{2}-\mathrm{CH}_{2}-\mathrm{Cl}$ );

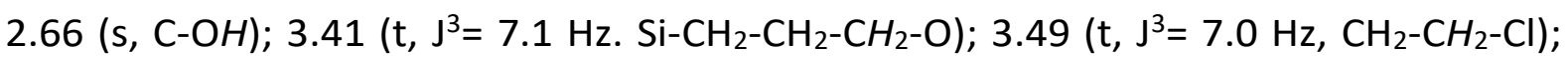
3.48 to $3.69\left(\mathrm{~m}, \mathrm{O}-\mathrm{CH}_{2}-\mathrm{CH}_{2}-\mathrm{O}\right)$.

${ }^{13} \mathrm{C} \mathrm{NMR}\left(\mathrm{CDCl}_{3}, \delta_{\mathrm{c}}, \mathrm{ppm}\right): 0.4$ to $1.6\left(\mathrm{Si}-\mathrm{CH}_{3}\right) ; 14.0\left(\mathrm{Si}-\mathrm{CH}_{2}-\mathrm{CH}_{2}-\mathrm{CH}_{2}-\mathrm{O}\right) ; 15.0\left(\mathrm{Si}-\mathrm{CH}_{2}-\right.$ $\left.\mathrm{CH}_{2}-\mathrm{CH}_{2}-\mathrm{Cl}\right) ; 23.1\left(\mathrm{Si}-\mathrm{CH}_{2}-\mathrm{CH}_{2}-\mathrm{CH}_{2}-\mathrm{O}\right) ; 26.7\left(\mathrm{Si}-\mathrm{CH}_{2}-\mathrm{CH}_{2}-\mathrm{CH}_{2}-\mathrm{Cl}\right) ; 47.6\left(\mathrm{Si}-\mathrm{CH}_{2}-\mathrm{CH}_{2}-\mathrm{CH}_{2}-\right.$ $\mathrm{Cl}) ; 70.5\left(\mathrm{O}-\mathrm{CH}_{2}-\mathrm{CH}_{2}-\mathrm{O}\right) ; 74.2\left(\mathrm{Si}-\mathrm{CH}_{2}-\mathrm{CH}_{2}-\mathrm{CH}_{2}-\mathrm{O}\right)$.

2.2.3 Synthesis of PEG-b-PDMS(N3)-b-PEG (3). 2 was dissolved in dry tetrahydrofuran (THF, $100 \mathrm{~mL})$ together with $\mathrm{NaN}_{3}(1.78 \mathrm{~g}, 27.4 \mathrm{mmol})$ and tetrabutylammonium azide $(0.156 \mathrm{~g}, 54.8 \mu \mathrm{mol})$. The reaction took place at the boiling temperature of THF $\left(\sim 66^{\circ} \mathrm{C}\right)$ under reflux for 72 hours. The reaction mixture obtained was filtered through a Teflon filter (pore size $\sim 0.45 \mu \mathrm{m}$ ) and was used without further purification.

IR (cm $\left.{ }^{-1}\right): 3470$ (-OH stretch); 2962 (C-H stretch); 2870 (aliphatic C-H stretch); 2097 ($\mathrm{N}_{3}$ stretch); 1258 (Si- $\mathrm{CH}_{3}$ deformation); $1070\left(\mathrm{CH}_{2}-\mathrm{O}-\mathrm{CH}_{2}\right.$ stretch); 1008 (Si-O-Si stretch); 785 (Si-C stretch).

${ }^{1} \mathrm{H}$ NMR $\left(\mathrm{CDCl}_{3}, \delta_{\mathrm{H}}, \mathrm{ppm}\right):-0.02$ to $0.05\left(\mathrm{~m}, \mathrm{Si}-\mathrm{CH}_{3}\right) ; 0.51\left(\mathrm{~m}, \mathrm{Si}-\mathrm{CH}_{2}-\mathrm{CH}_{2}-\mathrm{CH}_{2} \mathrm{O}\right) ; 1.61$ (m, Si-CH $\left.-\mathrm{CH}_{2}-\mathrm{CH}_{2}-\mathrm{O}\right) ; 2.66$ (s, C-OH); 3.22 (t, J3 $\left.=7.0 \mathrm{~Hz}, \mathrm{~N}_{3}-\mathrm{CH}_{2}-\mathrm{CH}_{2}\right) ; 3.41$ (t, J3= 7.1 $\left.\mathrm{Hz}, \mathrm{Si}-\mathrm{CH}_{2}-\mathrm{CH}_{2}-\mathrm{CH}_{2}-\mathrm{O}\right) ; 3.48$ to 3.69 (m, O- $\left.\mathrm{CH}_{2}-\mathrm{CH}_{2}-\mathrm{O}\right)$.

${ }^{13} \mathrm{C} \mathrm{NMR}\left(\mathrm{CDCl}_{3}, \delta \mathrm{c}, \mathrm{ppm}\right):-1.1$ to $1.6\left(\mathrm{Si}-\mathrm{CH}_{3}\right) ; 14.0\left(\mathrm{Si}-\mathrm{CH}_{2}-\mathrm{CH}_{2}-\mathrm{CH}_{2}-\mathrm{O}\right) ; 15.0\left(\mathrm{Si}-\mathrm{CH}_{2}-\right.$ $\left.\mathrm{CH}_{2}-\mathrm{CH}_{2}-\mathrm{O}\right) ; 23.1\left(\mathrm{Si}-\mathrm{CH}_{2}-\mathrm{CH}_{2}-\mathrm{CH}_{2}-\mathrm{O}\right) ; 54.1\left(\mathrm{~N}_{3}-\mathrm{CH}_{2}-\mathrm{CH}_{2}\right) ; 70.5\left(\mathrm{O}-\mathrm{CH}_{2}-\mathrm{CH}_{2}-\mathrm{O}\right) ; 74.2$ (Si$\left.\mathrm{CH}_{2}-\mathrm{CH}_{2}-\mathrm{CH}_{2}-\mathrm{O}\right)$. 
2.2.4 Synthesis of PEG-b-PDMS(coumarin)-b-PEG (4). 4-methyl-7-(prop-2-yn-1yloxy)-2H-chromen-2-one (1.18 g, $5.47 \mathrm{mmol})$ and Cul (77.2 $\mathrm{mg}, 0.41 \mathrm{mmol})$ were added to the reaction flask containing $\mathbf{3}$ and THF, and stirred for 15 minutes. Finally, distilled triethylamine $(0.554 \mathrm{~g}, 5.47 \mathrm{mmol})$ was added dropwise. The reaction took place at RT for 17 hours. The reaction mixture was then filtered by vacuum filtering (pore size $\sim 0.45 \mu \mathrm{m}$ ) and the THF was subsequently removed by rotatory evaporation under vacuum. The final product was purified by selective extraction with heptane and methanol to obtain the product in the form of a brown oil $\left(7.36 \mathrm{~g}, 34.5 \%, \mathrm{M}_{\mathrm{n}}=\right.$ $\left.3100 \mathrm{~g} / \mathrm{mol}, \mathrm{M}_{\mathrm{w}}=4100 \mathrm{~g} / \mathrm{mol}, \mathrm{D}=1.34\right)$

IR $\left(\mathrm{cm}^{-1}\right)$ : 3470 (-OH stretch); 2962 (C-H stretch); 2870 (aliphatic C-H stretch); 1258 (Si-CH $\mathrm{CH}_{3}$ deformation); 1070 ( $\mathrm{CH}_{2}-\mathrm{O}-\mathrm{CH}_{2}$ stretch); 1008 (Si-O-Si stretch); 785 (Si-C stretch).

${ }^{1} \mathrm{H}$ NMR $\left(\mathrm{CDCl}_{3}, \delta_{\mathrm{H}}, \mathrm{ppm}\right):-0.02$ to $0.05\left(\mathrm{~m}, \mathrm{Si}-\mathrm{CH}_{3}\right) ; 0.51\left(\mathrm{~m}, \mathrm{Si}-\mathrm{CH}_{2}-\mathrm{CH}_{2}-\mathrm{CH}_{2} \mathrm{O}\right) ; 1.61$ (m, Si-CH $\left.-\mathrm{CH}_{2}-\mathrm{CH}_{2}-\mathrm{O}\right) ; 2.66(\mathrm{~s}, \mathrm{C}-\mathrm{OH}) ; 3.41$ (t, J3 $=7.1 \mathrm{~Hz}, \mathrm{Si}-\mathrm{CH}_{2}-\mathrm{CH}_{2}-\mathrm{CH}_{2}-\mathrm{O}$ ); 3.48 to $3.69\left(\mathrm{~m}, \mathrm{O}-\mathrm{CH}_{2}-\mathrm{CH}_{2}-\mathrm{O}\right) ; 4.37\left(\mathrm{t}, \mathrm{J}^{3}=7.1 \mathrm{~Hz}, \mathrm{~N}_{3}-\mathrm{CH}_{2}-\mathrm{CH}_{2}\right) ; 6.15(\mathrm{~s}, 1 \mathrm{H}, \mathrm{O}=\mathrm{C}-\mathrm{CH}) ; 6.95(\mathrm{~m}$, $2 \mathrm{H}, \mathrm{Ar}-H) ; 7.50(\mathrm{~m}, 1 \mathrm{H}, \mathrm{Ar}-\mathrm{H}) ; 7.69(\mathrm{~s}, 1 \mathrm{H}, \mathrm{C}=\mathrm{CH}-\mathrm{N})$.

${ }^{13} \mathrm{C} \mathrm{NMR}\left(\mathrm{CDCl}_{3}, \delta_{\mathrm{c}}, \mathrm{ppm}\right): 0.4$ to $1.6\left(\mathrm{Si}-\mathrm{CH}_{3}\right) ; 14.0\left(\mathrm{Si}-\mathrm{CH}_{2}-\mathrm{CH}_{2}-\mathrm{CH}_{2}-\mathrm{O}\right) ; 23.1\left(\mathrm{Si}-\mathrm{CH}_{2}-\right.$ $\left.\mathrm{CH}_{2}-\mathrm{CH}_{2}-\mathrm{O}\right) ; 53.1\left(\mathrm{~N}_{3}-\mathrm{CH}_{2}-\mathrm{CH}_{2}\right) ; 70.5\left(\mathrm{O}-\mathrm{CH}_{2}-\mathrm{CH}_{2}-\mathrm{O}\right) ; 74.2\left(\mathrm{Si}-\mathrm{CH}_{2}-\mathrm{CH}_{2}-\mathrm{CH}_{2}-\mathrm{O}\right) ; 102.2$ (Ar-C-Ar); $122.8(\mathrm{Ar}-\mathrm{C}-\mathrm{Ar}) ; 122.8(\mathrm{C}=\mathrm{CH}-\mathrm{N})$.

\subsection{Preparation of PDMS films}

The PDMS films were prepared by mixing silanol-terminated polydimethylsiloxane (4000 cSt, Dow Corning) ( $5 \mathrm{~g}, 0.11 \mathrm{mmol}$ ) with a 16 -functional ethyl polysilicate alkoxysilane crosslinker (57 $\mathrm{mg}, 0.065 \mathrm{mmol}$ ), in the presence of xylene as solvent ( 10 wt\%). The synthesized and 
the commercial copolymer used were soluble in xylene. Dibutyltin dilaurate was added as catalyst for the crosslinking reaction ( $3.5 \mathrm{~mol} \%)$.

The synthesized triblock PEG-b-PDMS-b-PEG copolymer was added so it accounted for 4 $w t \%$ of the total weight in the dry film. A doctor blade applicator with a $480 \mu \mathrm{m}$ gap was used to apply the mixture on a poly(ethylene terephthalate) (PET) film, and cured for a week at room temperature (RT) in the laboratory. The free film obtained was investigated by confocal laser scanning microscopy as detailed below in section 2.5.5. Note that these PDMS films have two surfaces, one that has been in contact with air and one that has been in contact with the PET surface. The surface in contact with air will be referred to in the text as the "top" surface, while the one in contact with PET will be the "bottom" surface.

With the objective of investigating the biofouling resistance properties of the labelled block copolymer, two additional coating formulations were prepared. In the first of these coatings, no copolymer was added. In the second, the labelled copolymer was substituted with a commercial copolymer, which was similar to the labelled copolymer in structure and composition, though with no fluorescent dye in its backbone structure.

The three formulations described above were applied on PMMA substrates $(10 \times 20 \mathrm{~cm})$ using an 8-cm doctor blade applicator, with a $400 \mu \mathrm{m}$ gap and cured for a week at room temperature in the laboratory. The films applied on PMMA substrates were only used for immersion purposes, while the films applied on PET were used for CLSM investigations, as previously described.

\subsection{Static seawater exposure}


The three coatings described in section 2.3 were immersed in seawater in the Mediterranean Sea in Barcelona $\left(41^{\circ} 12^{\prime} 43^{\prime \prime} \mathrm{N}, 1^{\circ} 44^{\prime} 0^{\prime \prime} \mathrm{E}\right)$ to investigate their resistance towards biofouling. The panels were immersed in static conditions and visually inspected every three months. Further details regarding seawater exposure can be found elsewhere [32].

\subsection{Analytical methods}

2.5.1 Contact angle measurements. Dataphysics OCA20 was employed to study the contact angle of a water droplet on the PDMS films by the sessile drop method. A droplet of $25 \mu \mathrm{l}$ of millipore water was placed on the films, and the contact angle was measured every 2 seconds for 10 minutes. Nonetheless, only one point every 30 seconds is plotted in Figure 3 for clarity. Further details regarding contact angle measurements can be found elsewhere [31].

2.5.2 Liquid Chromatography. Size-exclusion chromatography (SEC) was conducted on a SEC system consisting of three different columns, an Agilent PLgel Mixed-C $(7.5 \times 300 \mathrm{~mm})+$ two Agilent PLgel Mixed-D (7.5 x $300 \mathrm{~mm})$ columns. Two detectors were employed in this study, a UV (Ultraviolet) and an ELS (Evaporative Light Scattering) detector. The UV detector operated at a wavelength of $254 \mathrm{~nm}$. Tetrahydrofuran (THF) was used as eluent at a flow rate of $1 \mathrm{~mL} / \mathrm{min}$ at $22^{\circ} \mathrm{C}$. The system was calibrated using PEG standards with different $\mathrm{M}_{\mathrm{w}}$ obtained from Sigma-Aldrich.

2.5.3 FTIR spectroscopy. Attenuated Total Reflectance Infrared Spectroscopy (ATR-FTIR) was conducted on a Thermo-Fischer is50 FT-IR with a universal attenuated total reflection 
(ATR) sampling accessory on a diamond crystal. Spectra of the different products from the synthesis were taken with $4 \mathrm{~cm}^{-1}$ resolution and 32 scans in the range of $4000-650 \mathrm{~cm}^{-1}$ at $25^{\circ} \mathrm{C}$.

2.5.4 NMR Spectroscopy. 1-D ${ }^{1} \mathrm{H}-\mathrm{NMR}$ and ${ }^{13} \mathrm{C}-\mathrm{NMR}$, and 2-D COSY and HSQC were used to analyse the chemical composition of the different products obtained during the synthetic procedure. The spectra were recorded on a $300 \mathrm{MHz}$ NMR Spectrometer from Spectrospin and Bruker, using $\mathrm{CDCl}_{3}$ as solvent at $25^{\circ} \mathrm{C}$, which was used to reference the spectra. The COSY and HSQC spectra have been used for the assignation of chemical shifts but are not shown.

2.5.5 Confocal Laser Scanning Microscopy (CLSM). A $2 \times 2 \mathrm{~cm}$ (approximately) area of the studied PDMS film was cut with a scalpel. The cut film was placed on top of a glass slide, and was covered with a cover glass. A droplet of Millipore water was placed between the two surfaces of the PDMS film and the glass substrate and cover, to ensure that no trapped air was placed between the PDMS and the glass. Then, the film between the two glass slides was placed in the confocal microscope for analysis.

A confocal laser scanning microscope (SP5-X, Leica Microsystem, Wetzlar, Germany) was used to visualize the coumarin-labelled copolymer in the PDMS film. A $355 \mathrm{~nm}$ ultraviolet (UV) laser was selected for excitation, while the emission was collected at $420-480 \mathrm{~nm}$. A 63x water immersion objective was employed, and the data collected was processed in Leica LAS AF Lite (Leica Microsystems), Volocity (Perkin Elmer) and ImageJ (open source). Images of the $x-y$ plane of the film $(105 \times 105 \mu \mathrm{m})$ were taken at different z-positions $(4 \mu \mathrm{m}$ spacing between consecutives analyses). 
It is usually assumed that the fluorescence intensity and the concentration of fluorescent dyes are directly proportional. This is valid if the quantum yield of a given concentration of dye is similar in the different environments studied, that is, the PDMS phase, the labelled copolymer phase and the PDMS-water interface. In addition, no self-quenching effects should take place between dyes. It has been assumed here that the fluorescence intensity detected in the PDMS film is directly proportional to the concentration of labelled copolymer.

\section{Results and discussion}

Physical addition of amphiphilic block copolymers is one of the most used strategies to modify the surface properties of polymeric materials such as adhesion, wettability and biocompatibility. To visualize the copolymer distribution in PDMS-based coatings and films, a novel coumarin-labelled copolymer was synthesized. The labelled copolymer was added to a PDMS coating and confocal scanning laser microscopy was subsequently employed to obtain information regarding the distribution of the copolymer within the coating film.

\subsection{Synthesis of the coumarin-labelled PEG-b-PDMS-b-PEG copolymer}

A fluorescent-labelled triblock PEG-b-PDMS-b-PEG copolymer was synthesized for visualization purposes. The synthetic procedure is shown in Figure 1. Briefly, the objective was to prepare a polydimethylsiloxane backbone with a functional chloropropyl pendant group and reactive end-groups (1), to further attach PEG moieties on the end-groups of the siloxane backbone (2) and later modify the chloride pendant group to label the PEG-bPDMS-b-PEG copolymer with a fluorescent dye (4). 
In the first step of the synthesis, the Piers-Rubinsztajn reaction was used to prepare the PDMS backbone of the triblock copolymer, having two reactive hydride end-groups and a chloride pendant group in the middle of the chain (1). Therefore, 3chloropropylmethyldimethoxysilane was reacted with a low molecular weight hydrideterminated dimethylsiloxane oligomer $(\sim 1500 \mathrm{~g} / \mathrm{mol})$ in each end. The hydride-terminated dimethylsiloxane oligomer was used in excess ( $\sim 50 \%$ excess) to supress polymerization (i.e. generation of long polymeric chains consisting of alternating dimethylsiloxane and 3chloropropylmethyldimethoxysilane units). The confirmation of the reaction was provided by total disappearance of methoxy groups from 3-chloropropylmethyldimethoxysilane, as shown by the loss of resonance at $\delta_{H}=3.32 \mathrm{ppm}$ and the disappearance of the distinctive stretch peak of the $-0-\mathrm{CH}_{3}$ group at $2832 \mathrm{~cm}^{-1}$ in FTIR. The advance of the reaction could also be followed by SEC, with the molecular weight showing an increase between 2 and 2.5 fold after completion of the reaction, albeit with a significant increase in the dispersity (D) (see Figure S1 in Supporting Information).

In the second step of the synthesis, platinum-catalysed hydrosilylation was used to react telechelic $\alpha$-allyl- $\omega$-hydroxyl-poly(ethylene glycol) ( $500 \mathrm{~g} / \mathrm{mol}$ ) with the hydride end-groups of the PDMS backbone of $\mathbf{1}$. In this step, mono-allyl-terminated PEG was used in excess ( $30 \%$ excess) to ensure that the reaction yield was as high as possible, so that full conversion of all end-groups was achieved. The appearance of the Si-C bonds with resonances at $\delta_{H}=0.44,1.53$ and $3.34 \mathrm{ppm}$ pointed to the successful formation of the propyl linkers between the allyl-terminated PEG and the PDMS backbone, in the form of Si$\mathrm{CH}_{2}-\mathrm{CH}_{2}-\mathrm{CH}_{2}-\mathrm{O}$ bonds. The reaction was further confirmed by the consumption of hydride groups, as proven by the disappearance of resonance at $\delta_{H}=4.74 \mathrm{ppm}$. The excess of allyl- 
PEG was removed by decantation upon completion of the reaction, and was further removed at the last step of the synthetic pathway by selective solvent extraction in heptane. Once the chloro-functional, triblock PEG-b-PDMS-b-PEG copolymer (2) was synthesized, the chloride was substituted for an azide group by nucleophilic substitution using sodium azide $\left(\mathrm{NaN}_{3}\right)$. This step of the reaction was followed by the formation of $\mathrm{N}_{3}-\mathrm{CH}_{2}$ - groups, as confirmed by the appearance of resonance at $\delta_{H}=3.23 \mathrm{ppm}$ and $\delta_{\mathrm{C}}=53.9 \mathrm{ppm}$. FTIR corroborated it by the appearance of the characteristic peak at $2097 \mathrm{~cm}^{-1}$, corresponding to the stretch of the azide group $\left(-\mathrm{N}_{3}\right)$. The SEC traces showed that the molecular weight of the product did not change in this step (see Figure S1 in Supporting Information).

In the last step of the synthetic pathway, click chemistry was used to functionalize $\mathbf{3}$ with a fluorescent label. The azide group of the copolymer was reacted with an alkyne-terminated coumarin molecule as shown in Figure 1, thereby covalently linking the coumarin dye to the backbone of the triblock copolymer and obtaining a coumarin-labelled PEG-b-PDMS-b-PEG copolymer (4). The extent of reaction was followed by the appearance of a $-\mathrm{C}=\mathrm{CH}-\mathrm{N}$ - group as confirmed by the resonance at $\delta_{H}=7.52 \mathrm{ppm}$. The successful labelling of the copolymer molecule was also proven by SEC results, with the peak corresponding to the triblock copolymer becoming visible in the UV-detector after the last synthetic step. The final copolymer obtained showed a $M_{w}$ of approximately $4100 \mathrm{~g} / \mathrm{mol}$ and a $D$ of 1.34 based on SEC results. However, minor traces of impurities from the synthetic procedure were observed (see the small peak at large elution time in Figure S1 of Supporting Information), which could not be removed from the final product. NMR and FTIR analysis showed that non-reacted mono-allyl-terminated PEG is the major component of this peak.

The coumarin molecule used, 7-hydroxy-4-methylcoumarin, is a small organic fluorescent molecule $(176.17 \mathrm{~g} / \mathrm{mol})$ with excitation wavelength in the UV range $\left(\lambda_{\mathrm{ex}}=380 \mathrm{~nm}\right)$ and 
emission wavelength in the visible range $\left(\lambda_{e m}=460 \mathrm{~nm}\right)$. It is noteworthy that the molecular weight of the pendant group of the labelled copolymer (i.e. the propyl linker + the azide group + the coumarin molecule) is approximately $300 \mathrm{~g} / \mathrm{mol}$, accounting for only $7 \%$ of the total molecular weight of the copolymer molecule. The coumarin dye used to label the copolymer molecule was chosen due to: (i) its low molecular weight compared to most available fluorescent labels, (ii) previous experience within our research group and (iii) availability.

\subsection{PEG-b-PDMS-b-PEG block copolymers as additives in PDMS coatings}

The purpose of this work was to develop a method to visualize the distribution and behaviour of polymer additives used in PDMS films. In this case, PDMS-PEG-based copolymers used as surface-active additives for PDMS-based coatings were chosen. To that purpose, the fluorescent-labelled PEG-b-PDMS-b-PEG copolymer was successfully synthesized and added as additive ( $\sim$ wt\%) to an uncured PDMS mixture, which was applied on a PET substrate.

The curing process of the PDMS film was carried out by a condensation reaction between $\alpha, \omega$-dihydroxy polydimethylsiloxane (i.e. silanol-terminated PDMS) and a crosslinker containing a number of ethoxy reactive groups as schematically depicted in Figure 2 . The process is usually known as room-temperature vulcanization (RTV). 


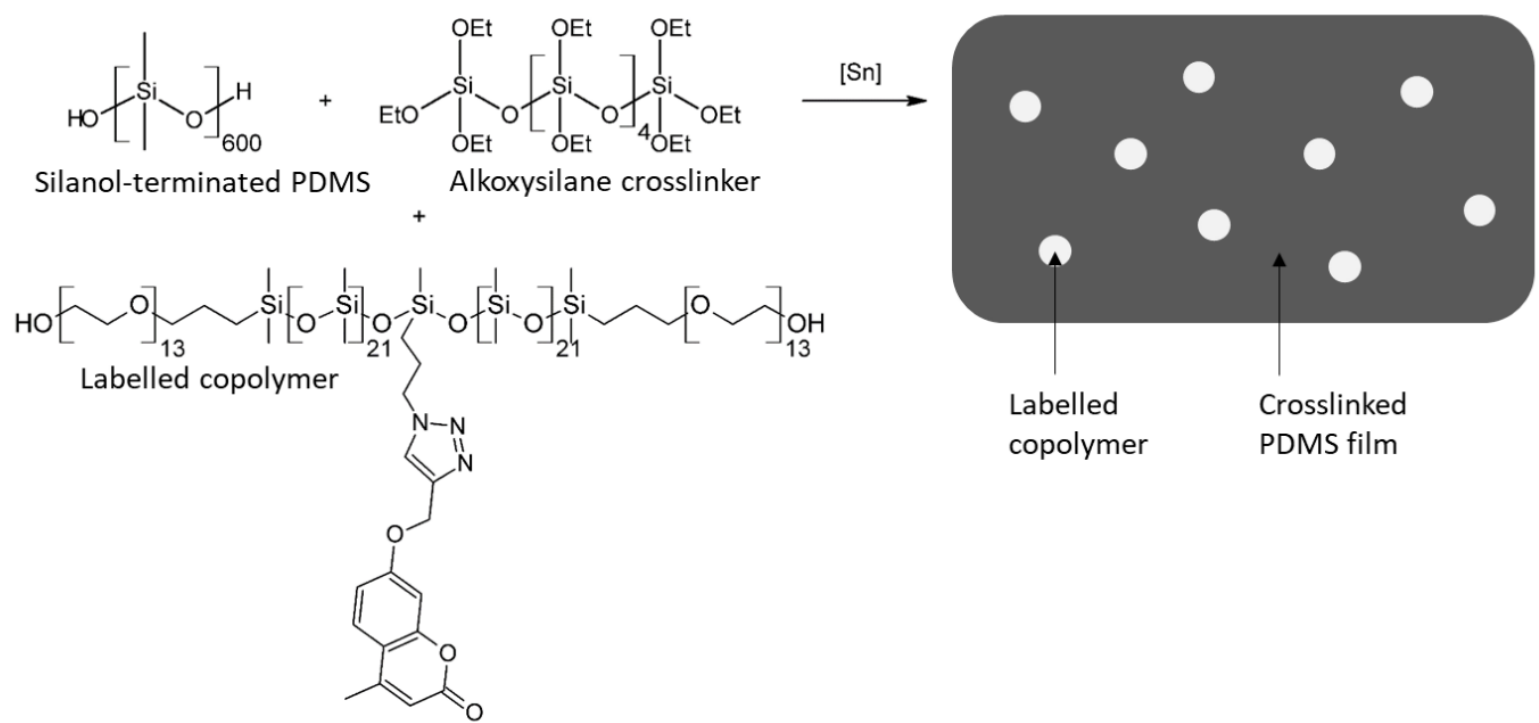

Figure 2. Sketch of the studied system, involving the crosslinking reaction of the PDMS film in the presence of the non-reactive labelled copolymer.

The hydroxyl end-groups of the PEG blocks of the copolymer do not react under these conditions, partly due to their significantly poorer properties as a nucleophile compared to the hydroxyl groups attached to the silicon atom of PDMS. This means that the solvent evaporates and the PDMS film is formed, but the added copolymer does not participate in the crosslinking process of the PDMS. Instead, the copolymer molecules remain non-bonded and can diffuse to the surface of the coating upon curing.

\subsection{Diffusion and surface-activity of the labelled PEG-b-PDMS-b-PEG copolymer}

A novel labelled copolymer has been synthesized and added to a PDMS coating as described above. The purpose was to elucidate the distribution and behaviour of commercial PDMSPEG-based copolymers in PDMS coatings and films by exploiting the fluorescence of the dye selected to label the synthesized copolymer. To ensure the validity of the results obtained with the labelled copolymer, it is first required to confirm that the behaviour of the synthesized copolymer successfully resembles that of the commercial copolymers usually 
employed. In other words, for the labelled copolymer to be a good model of the commercial copolymer it is mandatory that both molecules behave in a similar manner.

It has been previously shown [31] that the addition of commercial amphiphilic copolymers to PDMS films has an important effect on the surface properties of the films. These additives migrate from the bulk of the film to the surface, altering the physicochemical properties of the surface. As a result, the surface of the PDMS coating becomes hydrophilic and acquires biofouling resistance properties.

The change in hydrophilicity of the PDMS surface over time can be investigated by water contact angle measurements. Information regarding the energy and chemical composition of the studied surface can be obtained. Here, the migration and surface activity of the synthesized copolymer have been studied by this method. 


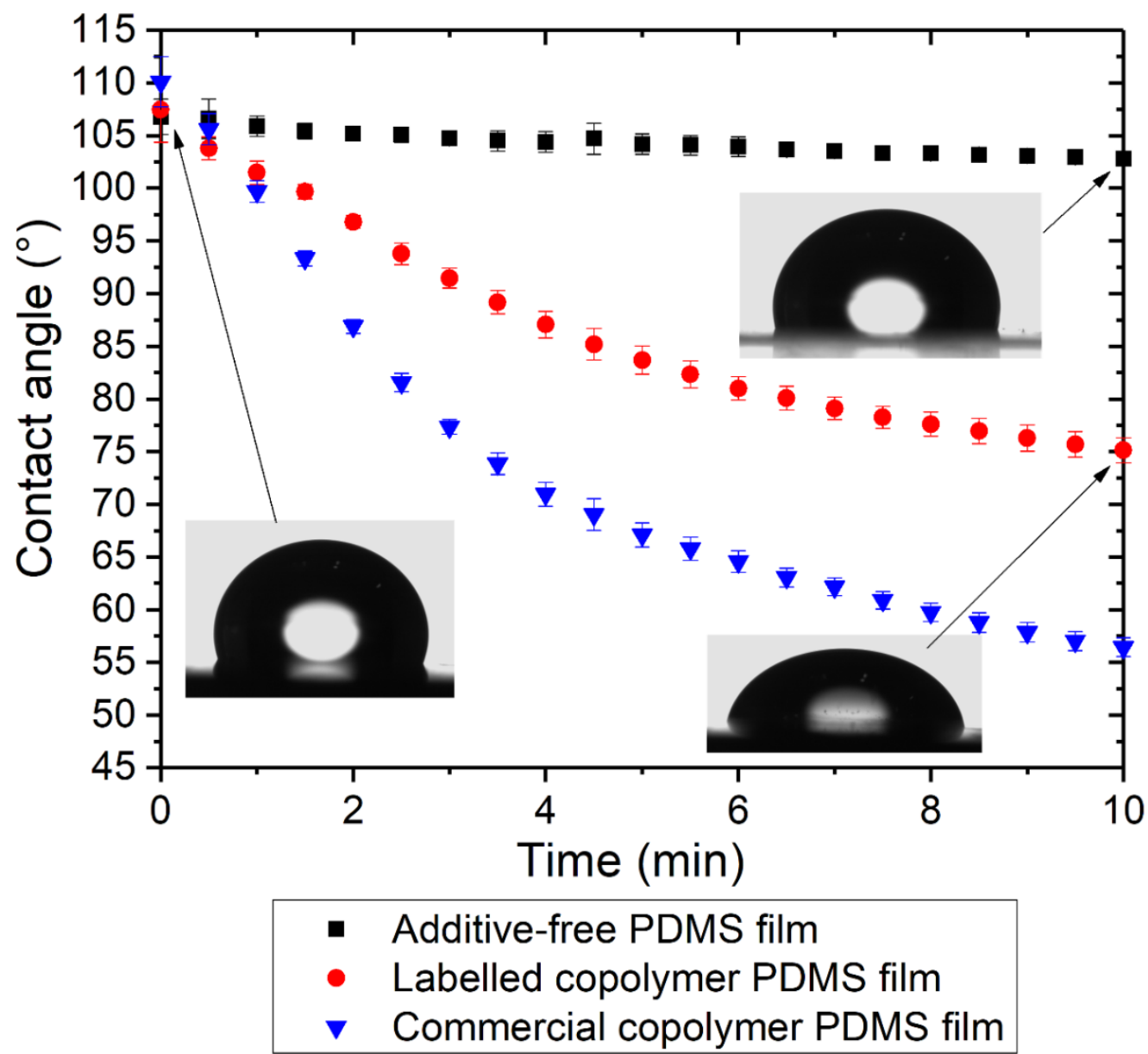

Figure 3. Water contact angle measurements of an additive-free (black squares) and two copolymer containing PDMS coatings, one containing the synthesized copolymer (red dots) and one containing a commercial copolymer (blue triangles).

Figure 3 shows the contact angle of a sessile water droplet on a PDMS coating containing 4 wt\% of the synthesized copolymer and compared to an additive-free PDMS film and a PDMS coating containing 4 wt\% of a commercial copolymer. The contact angle was measured for 10 minutes (thereafter the contact angle value remained relatively stable) and a clear difference can be seen. As expected, the additive-free PDMS film remains hydrophobic and only minor changes can be observed over time. Moreover, the contact angle of the modified PDMS films decrease over time, due to the presence of the amphiphilic copolymers, confirming the diffusion capabilities and surface-activity of both the synthesized and the commercial copolymer. The obtained values of the contact angle after 10 minutes shown in 
Figure 3 are in agreement with what has been reported for similar PEG-based amphiphilic molecules, with contact angles between $40^{\circ}$ and $80^{\circ}$ approximately $[28,31]$. However, it can be seen that there is a difference between the two copolymers, as the surface does not become as hydrophilic with the labelled copolymer as with the commercial.

The resistance towards biofouling of PDMS-based fouling-release coatings can be analysed by immersing the coatings in a seawater environment for several months.

Table 1 shows images of the three investigated coatings after different exposure times (unexposed, 3, 6 and 9 months). The level of biofouling on the investigated coatings shows significant variations, with some of the coatings being almost completely covered with biofouling, while others presenting a completely clean surface.

Similarly to what has been shown in Figure 3 , it can be seen that the addition of the synthesized copolymer to a PDMS coating enhances its biofouling resistance properties, as evidenced by the fact that coating 3 shows a completely clean surface after 3 months of exposure and a partially clean surface after 6 months, as compared to the biofouled surface of coating 1 in both cases. Nonetheless, its biofouling resistance properties are inferior compared to the commercial copolymer added in coating 2 .

It can be concluded from both contact angle and seawater exposure experiments that the labelled copolymer performs in a comparable, but not identical, manner to the commercial copolymer. 
Table 1. Images of three different coatings (coatings 1, 2 and 3) after different immersion times in seawater in Barcelona for 9 months. The three coatings are PDMS-based fouling-release coatings, with coating 1 containing no additive, coating 2 containing a commercial PDMS-PEG-based block copolymer and coating 3 containing the synthesized labelled copolymer.

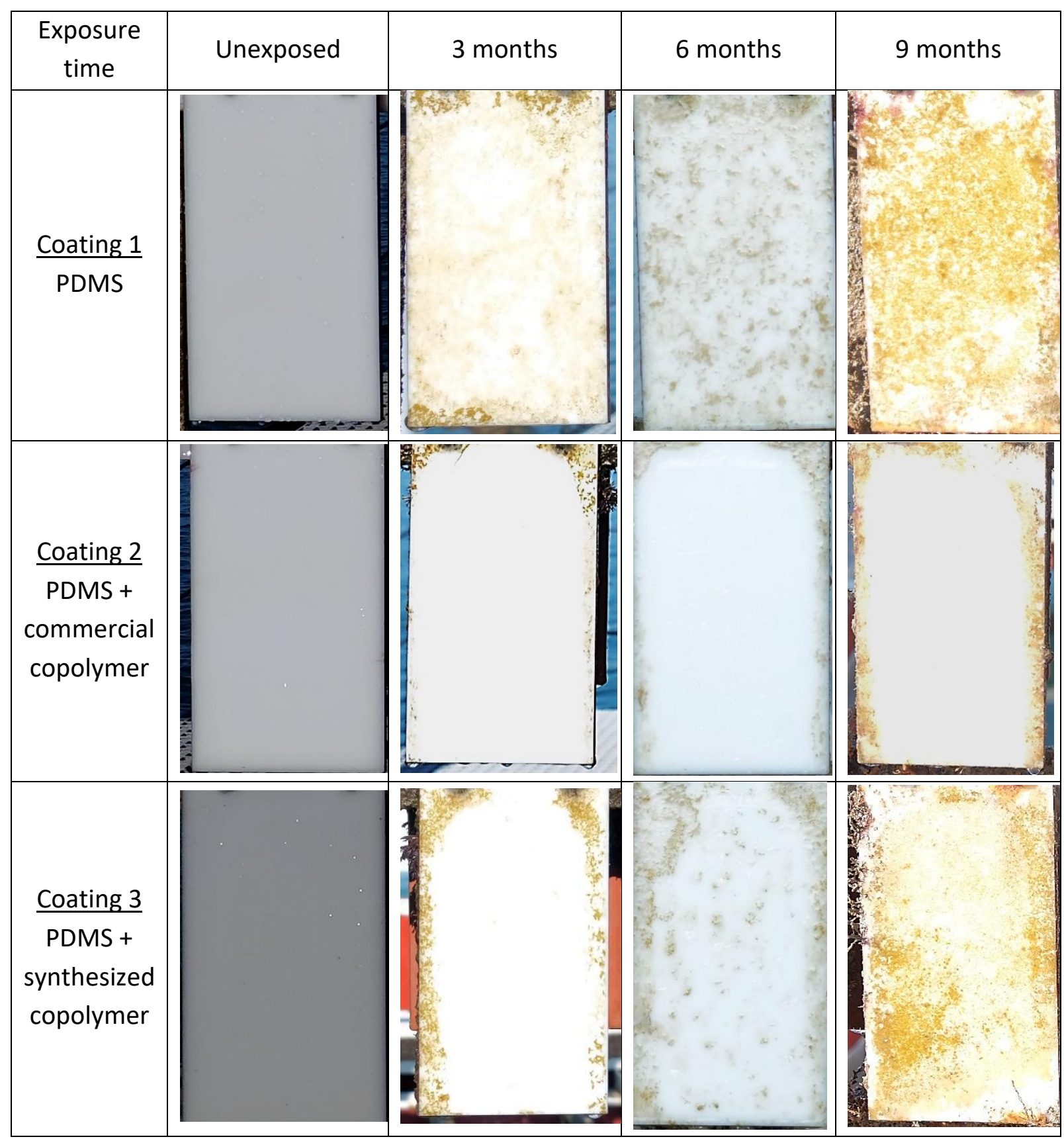




\subsection{Visualization of the labelled PEG-b-PDMS-b-PEG copolymer in the PDMS film}

With the aim of visualizing the distribution and the processes taking place in the bulk of the PDMS coating, confocal laser scanning microscopy (CLSM) has been employed to measure the distribution of the labelled triblock copolymer as a function of position and time. The PDMS film was placed on the confocal microscope and mounted between two glass slides in "wet conditions" (as described in section 2.5.5). The fluorescence intensity emitted by the copolymer was recorded at different z-positions. Note that the position $z=0 \mu \mathrm{m}$ (see Figures 5, 6 and 7 for more information) was arbitrarily taken at some point above the top surface of the PDMS film where no fluorescence could be detected, and values of $z>0$ indicate z-positions inside the PDMS film towards the bottom of the film, that was in contact during curing with the PET surface (see section 2.3 for more details) 


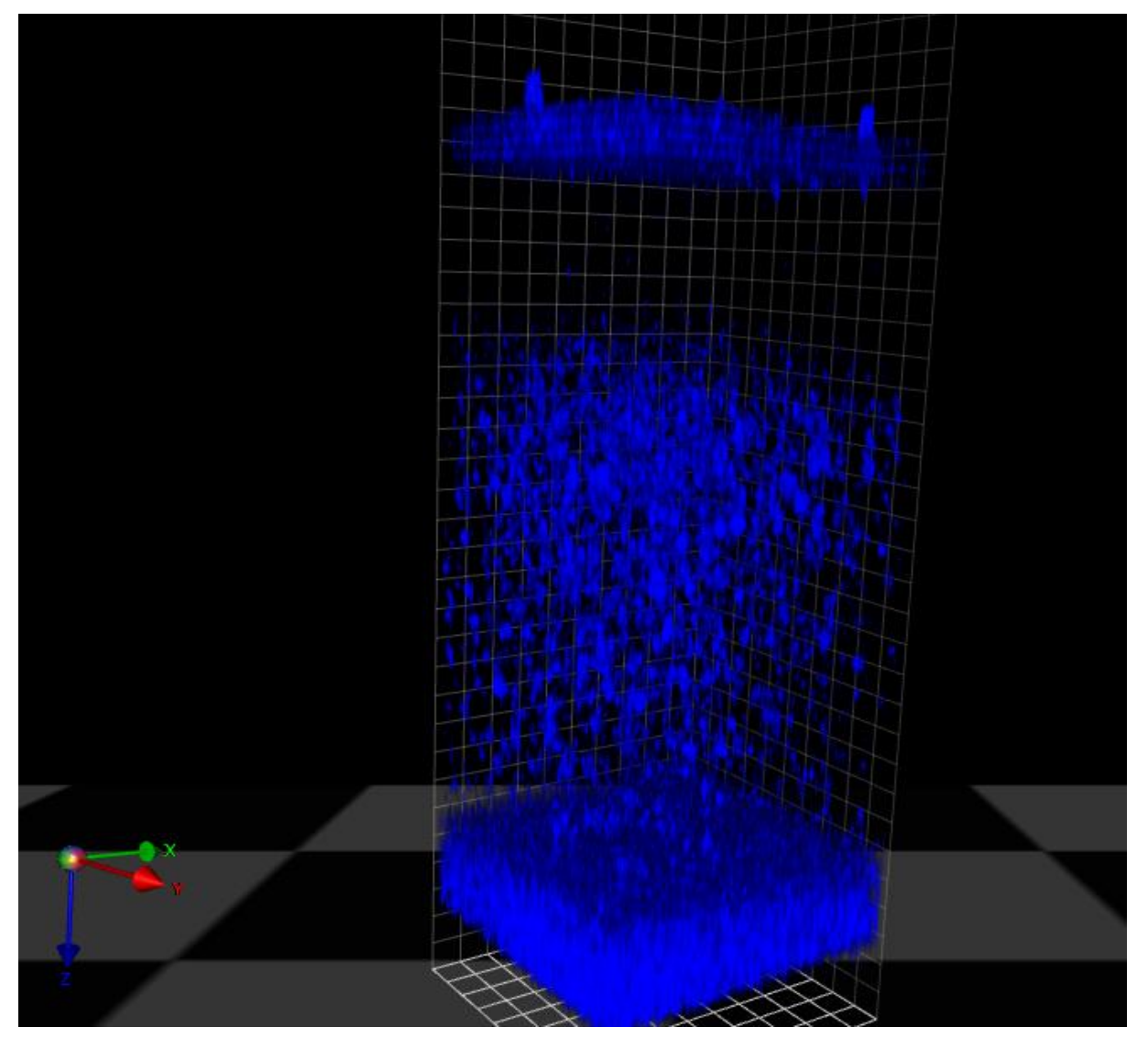

Figure 4. Projection obtained by confocal laser scanning microscopy (CLSM). The top of the image corresponds to the top of the film, that was cured in contact with air, while the bottom of the image corresponds to the bottom of the film, that was cured in contact with the PET substrate. The blue colour represents fluorescent activity of the coumarin-labelled copolymer. Formation of spherical domains of coumarin-labelled copolymer inside the PDMS film can be observed, as well as fluorescence intensity in the PDMS interfaces.

Figure 4 shows a 3-D stack of $135 x-y$ images collected at different z-positions (coating depths). It can be observed that the fluorescence emitted by the labelled copolymer is not evenly distributed throughout the film and different patterns can be seen.

In Figure 5, images of $x-y$ planes of the film at four different z-positions are presented: C1 $\left(z_{c 1}=90 \mu \mathrm{m}\right), C 2\left(z_{c 2}=128 \mu \mathrm{m}\right), C 3\left(z_{c 3}=192 \mu \mathrm{m}\right)$ and $\mathrm{C} 4\left(z_{c 4}=295 \mu \mathrm{m}\right)$. Some clear differences can be seen from the four images regarding the distribution of the copolymer in 
the PDMS coating. Images at C1, C2 and C3 show that the synthesized copolymer is distributed in spherical domains/aggregates inside the PDMS coating. The size of these domains varies depending on the z-position, being smaller closer to the top surface (C1) and larger in the bulk of the film $(C 2, C 3)$. Conversely, the image at the PDMS-water interface (C4) shows a different structure, with the triblock copolymer being homogeneously distributed within the $x-y$ plane, without any domain formation on the micron size range being detected.

It should be noted that the domains observed in Figures 4 and 5 have diameters of several microns. Usually, micro-phase separation is expected for these kind of systems, with micelles of different shapes and small domains being formed in the nanometre range. The observations reported in this investigation do not exclude micro-phase separation. However, the domains described belong to a larger structure. The relationship between this large structure and the microphase separation common in amphiphilic block copolymers was not explored. 


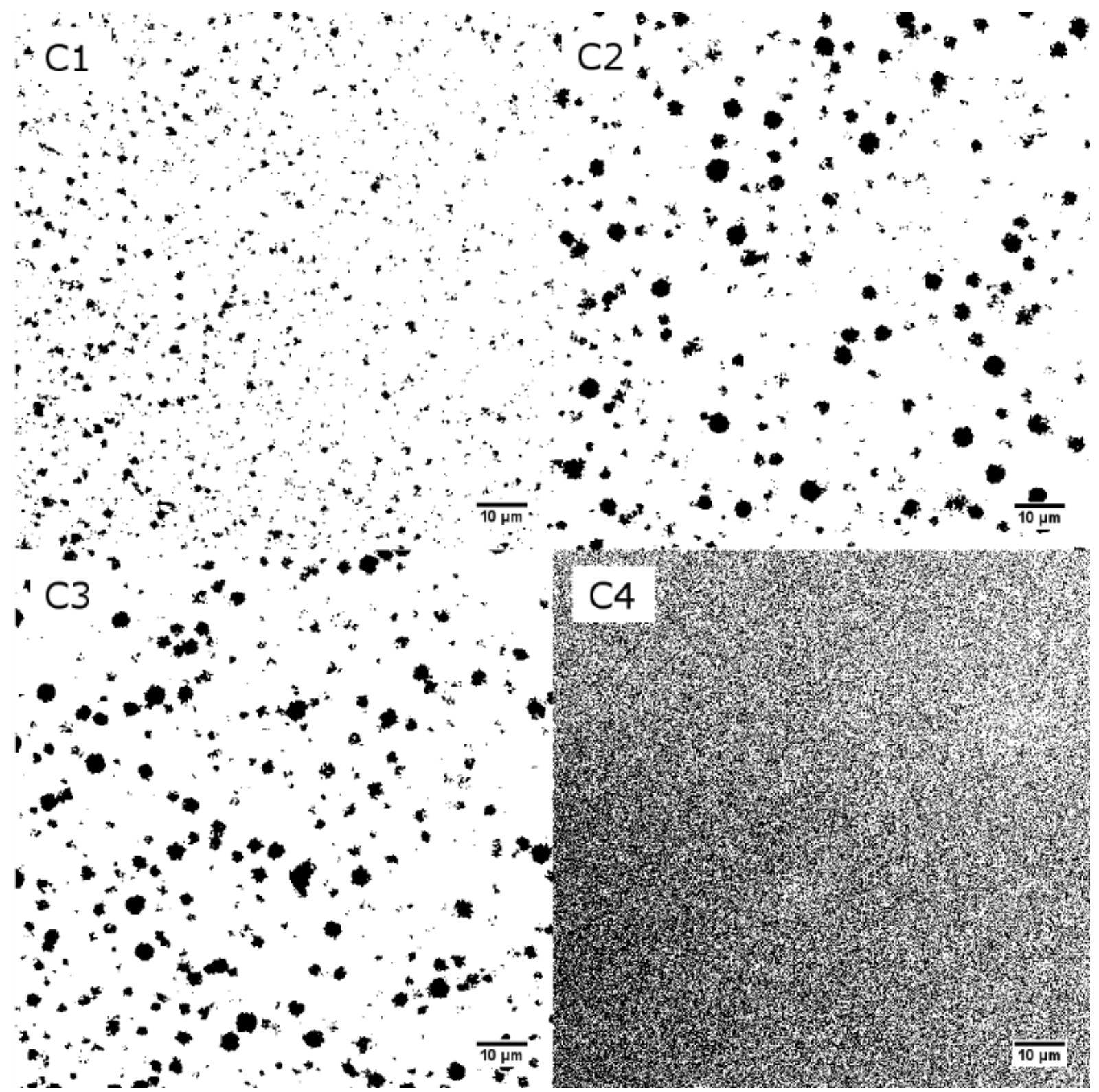

Figure 5. Fluorescence intensity images of the PDMS film at 4 different $z$-positions, 3 inside the

PDMS film, C1 $\left(z_{c 1}=90 \mu \mathrm{m}\right), C 2\left(z_{c 2}=128 \mu \mathrm{m}\right)$ and $C 3\left(z_{c 3}=192 \mu \mathrm{m}\right)$, and one at the PDMS-water interface, $\mathrm{C} 4\left(\mathrm{z}_{\mathrm{c} 4}=295 \mu \mathrm{m}\right)$. All the measurements were undertaken at $25^{\circ} \mathrm{C}$. The thickness of the PDMS film was measured by optical microscopy means in dry conditions to be approximately 210 $\mu \mathrm{m}$.

With the objective of better understanding the structure observed above, the size of the spherical domains was analysed by use of image analysis software. To that purpose, Volocity and ImageJ softwares were employed. Volocity has some tools which allow for recognition and analysis of 3-D entities in stacks of $x-y(2-D)$ images. Volocity returns some parameters 
of the entities detected (the copolymer spherical domains in this case), such as position, volume and shape factor, among others. Note, however, that a detection limit of approximately $1 \mu \mathrm{m}$ applies to this software, as below this value it is difficult to assess the presence of these spherical domains. Simultaneously, ImageJ software was employed to study the size of the domains at different z-positions from images obtained at different depths (see for example the images shown in Figure 5). ImageJ identifies circumferences in 2-D images, and returns the area and position of each recognized circumference. The diameter of the circumference is calculated and assumed to be equal to the diameter of the spherical domain in which it is contained. The drawback of this approach is that each circumference detected is assumed to represent the largest section of a given spherical domain, which is not necessarily true. The results obtained from ImageJ are therefore expected to underestimate the real diameter of the copolymer domains. The results from both methods, however, are expected to be comparable.

Figure 6 shows the diameter of each individual copolymer domain inside the PDMS film against the z-position of its centre based on the results provided by Volocity. Moreover, the average of the largest $25 \%$ domains in each z-position provided by ImageJ is plotted as black dots for comparison. Note that the average of the largest $25 \%$ domains for each depth was chosen to better illustrate the importance of the large domains in each depth, and minimize to some extent the effect of the large amount of small domains detected. The small domains detected by ImageJ are assumed to be a combination of small domains and larger domains which have the centre in another z-position, and therefore only a small slice of the spherical domain is visible at a certain z-position. Note also that below $60 \mu \mathrm{m}$ and above 270 $\mu \mathrm{m}$ no domains within the detection limits of the techniques could be detected. 


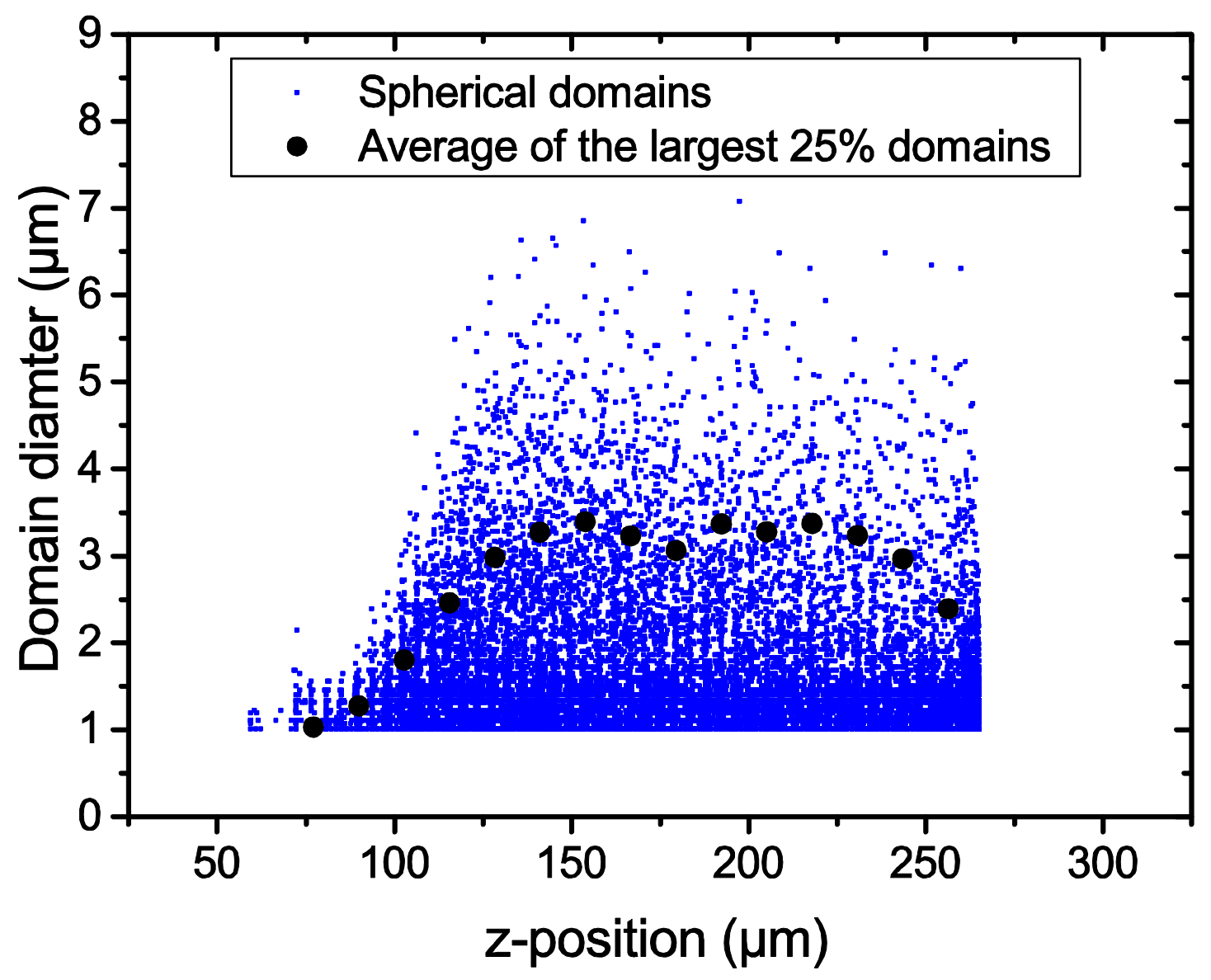

Figure 6. Diameter of the spherical domains of coumarin-labelled copolymer as a function of zposition (blue, obtained with Volocity) and the average of the biggest $25 \%$ domains at different $z$ positions (black, obtained with ImageJ).

It can be clearly seen that there is a z-position dependence of the size of the copolymer domains, with small domains being present on the top surface of the film (approximately from $z=60 \mu \mathrm{m}$ to $z=100 \mu \mathrm{m})$, which become larger until a maximum of around 7 microns is reached, as shown in Figure 6. After that, the size of the domains remains stable. These results are in agreement with the images at different depths presented in Figure 5 . A slight decrease in size can be seen at the bottom of the film.

The difference in domain size between the surface and the bulk of the film may be attributed to different reasons. Due to the higher concentration of moisture (a reactant in the PDMS crosslinking reaction) and faster solvent evaporation rates, the film is initially 
crosslinked on the top surface, while the crosslinking in the bulk of the film takes place at a later stage. The crosslinking of the film results in a decrease in the free volume and therefore the copolymer molecules might migrate to the bulk of the film. Furthermore, the faster evaporation of xylene from the top surface, together with the low solubility of the copolymer in PDMS can also be a reason for the copolymer to assemble into spherical domains in the bulk of the film and thus decrease the energy penalty associated with the interfacial area between the copolymer and the PDMS matrix.

Another factor that could influence the distribution of the investigated copolymer within PDMS-based films is the presence of a siliceous phase. It has been shown by Ogoshi et al. [41] that the curing of PDMS elastomers via the condensation mechanism results in the formation of a siliceous phase. The presence of these siliceous domains could therefore influence the distribution of the copolymer within the coating film, but has not been further investigated.

\subsection{Migration of the labelled PEG-b-PDMS-b-PEG copolymer}

To study possible variations over time in the distribution of the copolymer in the PDMS film, it was decided to analyse the PDMS coating on the same spot at different times. Three measurements were undertaken with 15 minutes between consecutive scans and the results are plotted in Figure 7, where the fluorescence intensity vs the z-position is shown for three different times. 


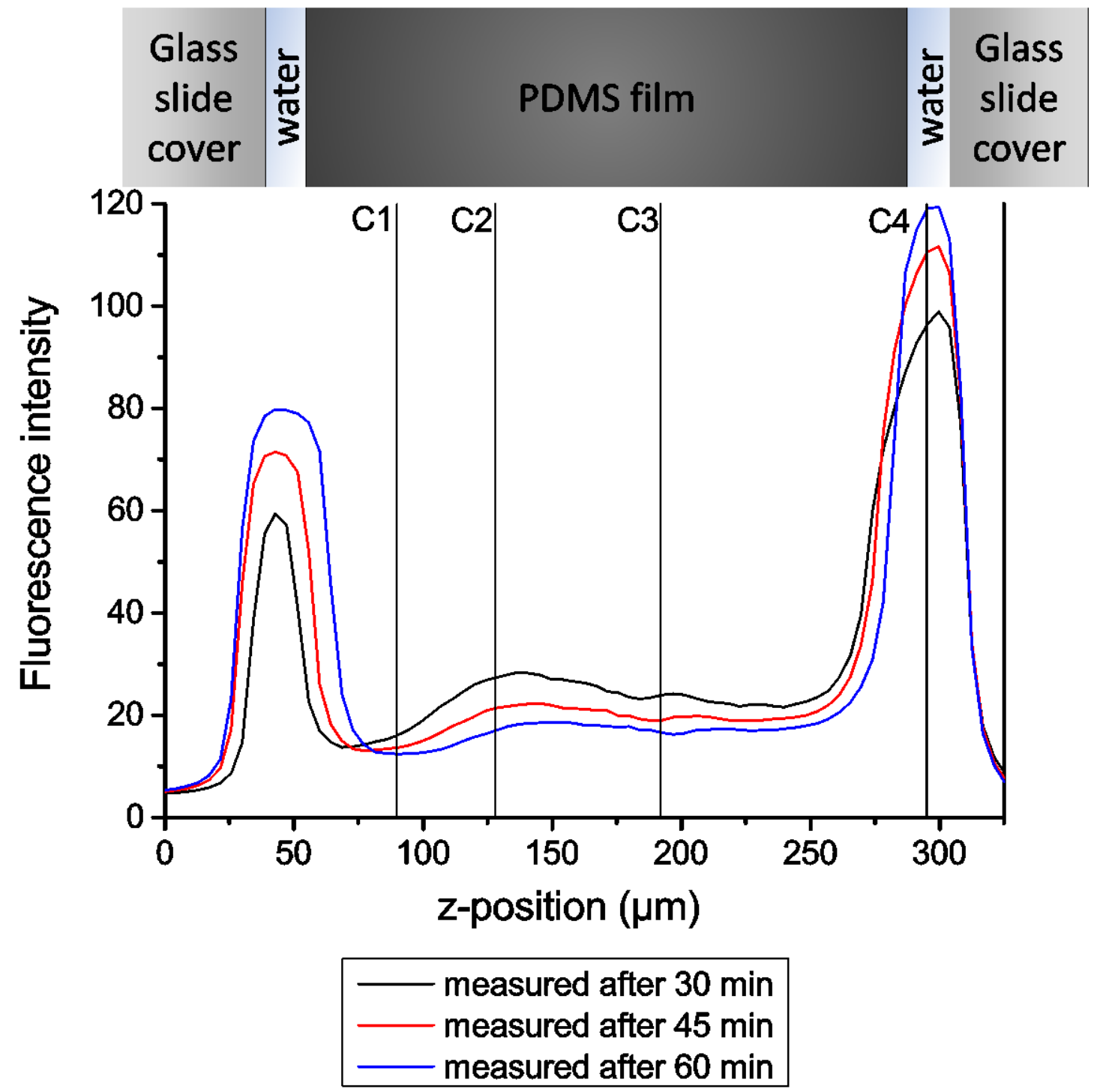

Figure 7. Fluorescence intensity distribution as a function of the z-position (depth) for the same PDMS film measured at three different times. The z-position of the images shown in Figure 5 at three different depths inside the coating film (C1, C2, C3) and at one of the PDMS-water interface (C4) are marked with black solid lines. For calculation, the baseline has been established connecting the first and last points of the plot (i.e. at $z=0$ and $z=325 \mu \mathrm{m}$ ).

As shown in Figure 7, the distribution of the labelled copolymer varies over time. Three main conclusions can therefore be drawn from Figure 7. First, there is a significant amount of copolymer at the interfaces of the PDMS film. Assuming that the quantum yield of the fluorescent label is similar in the PDMS bulk and PDMS-water interface (see section 2.5.5), the copolymer is distributed approximately equally between the top interface, the bulk of 
the film and the bottom interface, with approximately one third of the copolymer molecules being present in each of these three areas (see also Figure S2 in Supporting Information). Secondly, the fluorescence intensity is not constant throughout the film, i.e., the synthesized copolymer has a tendency to distribute unevenly. This is in agreement with the previous results, showing that the domains vary in size and concentration with the zposition. Finally, a change in fluorescence over time can be seen if the three experiments are compared, with the fluorescence intensity decreasing in the bulk of the film, which increases at the two PDMS-water interfaces. Although the change in fluorescence intensity is significant in such a short amount of time, our previous work proved that surface-active PDMS-PEG-based copolymers added as additives in PDMS coatings can diffuse through PDMS films of $168 \mu \mathrm{m}$ in approximately 30 minutes [31]. A plot of the accumulative fluorescence vs the z-position (see Figure S2 in Supporting Information) confirms that the total amount of fluorescence remains constant throughout the three measurements, confirming the migration of the synthesized triblock copolymer. By comparison of Figures 6 and 7, it can be hypothesized that the smaller domains on the top surface of the PDMS film are due to depletion. That is, the copolymer molecules initially contained in the spherical domains close to the surface migrated to the surface of the film, thus leaving behind a layer of PDMS with low amounts of copolymer, contained in small-sized domains. It should be noted that the two surfaces (top and bottom) of the studied PDMS films might present significant differences. These arise from the curing process of the film, in which the top surface was exposed to air (i.e. higher xylene evaporation rate and initial crosslinking) and the bottom surface was in contact with the PET film. Note that the top surface of the studied PDMS films corresponds to the surface exposed to seawater in the results presented in Table 1 (static seawater immersion experiments). 
The results shown in Figures 4-7 have some similarities to those observed by Cui et al. [37], who studied the secretion of a hydrophobic silicone oil in a supramolecular polymer matrix. A PDMS oil was embedded in a PDMS-urea polymer, which was reversibly crosslinked by hydrogen bonds between the urea groups. Their results showed a system with a layer of high concentration of silicone oil on the surface, followed by a droplet-free layer and, after that, the bulk of the film with droplets of silicone oil embedded in the polymer-gel matrix.

\subsection{Future applications in fouling-release coatings}

In the present work, the distribution and migration of triblock PEG-b-PDMS-b-PEG copolymers in PDMS-based fouling-release coatings have been studied. Due to the flexibility of the synthetic pathway presented, different modifications could be introduced to further improve the understanding of these systems. Hence, the effect of the molecular weight of the copolymer and the relative molecular weight of its blocks on the distribution and migration of the copolymer could be studied. In other words, the reactants chosen in the synthetic steps 1 and 2 (i.e. the PDMS and PEG oligomers) could be substituted with analogues of larger or smaller molecular weight. In the case of the PEG block, oligomers with a different end-group could be chosen. The effect of the molecular weight and endgroup of the PEG chains have been extensively studied on different surfaces [33], but little work has been done regarding the behaviour of these compounds within the bulk of PDMS films.

Likewise, more significant variations could be considered. The PEG block of the copolymer could be substituted by other hydrophilic polymers such as poly(acrylic acid) or poly(vinyl alcohol) to mention some examples, and elucidate the influence of the chemistry of the hydrophilic block on the aforementioned phenomena. Likewise, some parameters and 
properties of the PDMS binder could be changed, such as the molecular weight of the PDMS in the binder, the curing agent used, the crosslinking density or the solvent employed. Finally, different PDMS-based block copolymers could be synthesized and labelled with different dyes. In that way, all the different PDMS-based copolymers could be simultaneously added to a PDMS film and independently visualized at the same time by use of different radiation wavelengths.

In spite of the great amount of possibilities and advantages offered by the presented methodology, it should be noted that there exist some limitations. There is an important amount of synthetic work in the laboratory prior to the acquisition of results. Moreover, as previously explained, the technique has some limitations in terms of detection limits and composition of PDMS films.

\section{Conclusions}

A novel coumarin-labelled triblock PEG-b-PDMS-b-PEG copolymer has been synthesized for visualization purposes combining the Piers-Rubinsztajn reaction, the hydrosilylation reaction and click chemistry in a robust and versatile synthetic pathway. The surface-activity of the synthesised copolymer has been confirmed by contact angle measurements and biofouling resistance experiments. The labelled copolymer has been used as additive in a PDMS- based coating, which has been studied by confocal microscopy and subsequently by image analysis software.

It has been shown that the synthesized copolymer tends to aggregate into spherical domains inside the PDMS film. Domains as large as $7 \mu \mathrm{m}$ in diameter have been observed, and it has been found that the size of the domains depends on the z-position, with small domains being present close to the surface, while larger domains exist in the bulk of the 
PDMS film. Likewise, the concentration of the copolymer inside the film varies with the zposition (depth). A significant amount of copolymer was observed homogeneously distributed in the interfaces of the film, presenting a different distribution pattern than in the bulk of the film where spherical domains could be observed. Finally, it has been shown that the distribution of the copolymer in the film changes over time, with copolymer diffusing from the bulk of the film towards its interfaces, in agreement with the expected surface-activity of these amphiphilic copolymers. In summary, the versatile method presented allows for visualization and understanding of complex systems such as the distribution and diffusion of surface-active block copolymers in PDMS films.

\section{Acknowledgements}

Financial support of the Danish Ministry of Higher Education and Science and the Independent Research Fund is gratefully acknowledged. Help from colleagues at the Danish Polymer Centre (DPC-DTU) and at the Department of Plant and Environmental Science at University of Copenhagen is also acknowledged.

\section{References}

[1] A. Hisyam A. Razak, P. Szabo, A.L. Skov, Enhancement of dielectric permittivity by incorporating PDMS-PEG multiblock copolymers in silicone elastomers, RSC Adv. 5 (2015) 53054-53062. doi:10.1039/C5RA09708H.

[2] J. Seo, L.P. Lee, Effects on wettability by surfactant accumulation/depletion in bulk polydimethylsiloxane (PDMS), Sensors Actuators, B Chem. 119 (2006) 192-198. doi:10.1016/j.snb.2005.12.019. 
[3] A.G. Nurioglu, A.C.C. Esteves, G. de With, Non-toxic, non-biocide-release antifouling coatings based on molecular structure design for marine applications, J. Mater. Chem. B. 3 (2015) 6547-6570. doi:10.1039/C5TB00232J.

[4] M.A. Champ, A review of organotin regulatory strategies, pending actions, related costs and benefits, Sci. Total Environ. 258 (2000) 21-71. doi:10.1016/S00489697(00)00506-4.

[5] R.F. Brady, I.L. Singer, Mechanical factors favoring release from fouling release coatings, Biofouling. 15 (2000) 73-81. doi:10.1080/08927010009386299.

[6] M.E. Callow, R.L. Fletcher, The influence of low surface energy materials on bioadhesion-a review, Int. Biodeterior. Biodegradation. 34 (1994) 333-348. doi:10.1016/0964-8305(94)90092-2.

[7] M.A. Brook, Silicon in organic, organometallic, and polymer chemistry, John Wiley \& Sons, New York, 2000.

[8] F.B. Madsen, A.E. Daugaard, S. Hvilsted, A.L. Skov, The Current State of Silicone-Based Dielectric Elastomer Transducers, Macromol. Rapid Commun. 37 (2016) 378-413. doi:10.1002/marc.201500576.

[9] Z. Wu, K. Hjort, Surface modification of PDMS by gradient-induced migration of embedded Pluronic, Lab Chip. 9 (2009) 1500. doi:10.1039/b901651a.

[10] H. Madadi, J. Casals-Terré, Long-term behavior of nonionic surfactant-added PDMS for self-driven microchips, Microsyst. Technol. 19 (2013) 143-150. doi:10.1007/s00542-012-1641-7. 
[11] D. Bodas, C. Khan-Malek, Hydrophilization and hydrophobic recovery of PDMS by oxygen plasma and chemical treatment-An SEM investigation, Sensors Actuators B Chem. 123 (2007) 368-373. doi:10.1016/j.snb.2006.08.037.

[12] T. Røn, I. Javakhishvili, S. Hvilsted, K. Jankova, S. Lee, Ultralow Friction with Hydrophilic Polymer Brushes in Water as Segregated from Silicone Matrix, Adv. Mater. Interfaces. 3 (2016) 1500472. doi:10.1002/admi.201500472.

[13] H. Lee, L.A. Archer, Functionalizing Polymer Surfaces by Field-Induced Migration of Copolymer Additives. 1. Role of Surface Energy Gradients, Macromolecules. 34 (2001) 4572-4579. doi:10.1021/ma001278e.

[14] R.C. Bowers, N.L. Jarvis, W.A. Zisman, Reduction of Polymeric Friction by Minor Concentrations of Partially Fluorinated Compounds, Ind. Eng. Chem. Prod. Res. Dev. 4 (1965) 86-92. doi:10.1021/i360014a007.

[15] P.C.W. Thorlaksen, A. Blom, U. Bork, Novel fouling control coating compositions, WO2011076856, 2011.

[16] P.C.W. Thorlaksen, Fouling control coating compositions comprising polysiloxane and pendant hydrophilic oligomer/polymer moieties, WO2013000478, 2013.

[17] D.C. Webster, R.B. Bodkhe, Functionalized silicones with polyalkylene oxide side chains, WO2013052181, 2013.

[18] K.J. Reynolds, B. V. Tyson, Anti-fouling compositions with a fluorinated oxyalkylenecontaining polymer or oligomer, WO 2014131695, 2014.

[19] J. Stein, T.B. Brydon, J.A. Cella, Condensation curable silicone foul release coatings 
and articles coated therewith, US006107381, 2000.

[20] W.P. Liao, Antifouling system comprising silicone hydrogel, WO 2014126643, 2014.

[21] S. Tanino, Antifouling coating composition, antifouling coating film, antifouling substrate, and method for improving storage stability of antifouling coating composition, EP2921538, 2015.

[22] J. Dewitte, G. Piessens, R. Dams, Fluorochemical intermediates, surfactants and their use in coatings, JOCCA - Surf. Coatings Int. 78 (1995) 58-64.

[23] A.P. Narrainen, L.R. Hutchings, I. Ansari, R.L. Thompson, N. Clarke, Multi-EndFunctionalized Polymers: Additives to Modify Polymer Properties at Surfaces and Interfaces, Macromolecules. 40 (2007) 1969-1980. doi:10.1021/ma062349y.

[24] E. Berndt, S. Behnke, A. Dannehl, A. Gajda, J. Wingender, M. Ulbricht, Functional coatings for anti-biofouling applications by surface segregation of block copolymer additives, Polymer (Guildf). 51 (2010) 5910-5920. doi:10.1016/j.polymer.2010.10.002.

[25] R.B. Bodkhe, S.J. Stafslien, N. Cilz, J. Daniels, S.E.M. Thompson, M.E. Callow, J.A. Callow, D.C. Webster, Polyurethanes with amphiphilic surfaces made using telechelic functional PDMS having orthogonal acid functional groups, Prog. Org. Coatings. 75 (2012) 38-48. doi:10.1016/j.porgcoat.2012.03.006.

[26] H.S. Sundaram, Y. Cho, M.D. Dimitriou, C.J. Weinman, J.A. Finlay, G. Cone, M.E. Callow, J.A. Callow, E.J. Kramer, C.K. Ober, Fluorine-free mixed amphiphilic polymers based on PDMS and PEG side chains for fouling release applications, Biofouling. 27 
(2011) 589-602. doi:10.1080/08927014.2011.587662.

[27] C.J. Kavanagh, G.W. Swain, B.S. Kovach, J. Stein, C. Darkangelo-Wood, K. Truby, E. Holm, J. Montemarano, A. Meyer, D. Wiebe, The Effects of Silicone Fluid Additives and Silicone Elastomer Matrices on Barnacle Adhesion Strength, Biofouling. 19 (2003) 381-390. doi:10.1080/08927010310001623296.

[28] H.T. Kim, J.K. Kim, O.C. Jeong, Hydrophilicity of surfactant-added poly(dimethylsiloxane) and its applications, Jpn. J. Appl. Phys. 50 (2011). doi:10.1143/JJAP.50.06GL04.

[29] Y.C. Kim, S.H. Kim, D. Kim, S.J. Park, J.K. Park, Plasma extraction in a capillary-driven microfluidic device using surfactant-added poly(dimethylsiloxane), Sensors Actuators, B Chem. 145 (2010) 861-868. doi:10.1016/j.snb.2010.01.017.

[30] Y. Xiao, X.D. Yu, J.J. Xu, H.Y. Chen, Bulk modification of PDMS microchips by an amphiphilic copolymer, Electrophoresis. 28 (2007) 3302-3307. doi:10.1002/elps.200700024.

[31] A. Camós Noguer, S.M. Olsen, S. Hvilsted, S. Kiil, Diffusion of surface-active amphiphiles in silicone-based fouling-release coatings, Prog. Org. Coatings. 106 (2017) 77-86. doi:10.1016/j.porgcoat.2017.02.014.

[32] A. Camós Noguer, S.M. Olsen, S. Hvilsted, S. Kiil, Field study of the long-term release of block copolymers from fouling-release coatings, Prog. Org. Coatings. 112 (2017). doi:10.1016/j.porgcoat.2017.07.001.

[33] A. Camós Noguer, S.M. Olsen, S. Hvilsted, S. Kiil, Long-term stability of PEG-based 
antifouling surfaces in seawater, J. Coatings Technol. Res. 13 (2016) 567-575. doi:10.1007/s11998-016-9801-9.

[34] C. Kósa, M. Danko, A. Fiedlerová, P. Hrdlovic, E. Borsig, R.G. Weiss, Pyrenyl Fluorescence as a Probe of Polymer Structure and Diffusion in a Polyethylene:Poly(butyl methacrylate)- co -polystyrene Interpenetrating Network and Related Polymers, Macromolecules. 34 (2001) 2673-2681. doi:10.1021/ma0019151.

[35] T.J. Martin, S.E. Webber, Fluorescence Studies of Polymer Micelles: Intracoil Direct Energy Transfer, Macromolecules. 28 (1995) 8845-8854. doi:10.1021/ma00130a019.

[36] A. Konash, M.J. Cooney, B.Y. Liaw, D.M. Jameson, Characterization of enzymepolymer interaction using fluorescence, J. Mater. Chem. 16 (2006) 4107-4109. doi:10.1039/B611686H.

[37] J. Cui, D. Daniel, A. Grinthal, K. Lin, J. Aizenberg, Dynamic polymer systems with selfregulated secretion for the control of surface properties and material healing, Nat. Mater. 14 (2015) 1-6. doi:10.1038/nmat4325.

[38] F.B. Madsen, I. Javakhishvili, R.E. Jensen, A.E. Daugaard, S. Hvilsted, A.L. Skov, Synthesis of telechelic vinyl/allyl functional siloxane copolymers with structural control, Polym. Chem. 5 (2014) 7054-7061. doi:10.1039/C4PY00919C.

[39] F.B. Madsen, A.E. Daugaard, C. Fleury, S. Hvilsted, A.L. Skov, Visualisation and characterisation of heterogeneous bimodal PDMS networks, RSC Adv. 4 (2014) 69396945. doi:10.1039/C3RA47522K.

[40] F.B. Madsen, I. Dimitrov, A.E. Daugaard, S. Hvilsted, A.L. Skov, Novel cross-linkers for 
PDMS networks for controlled and well distributed grafting of functionalities by click chemistry, Polym. Chem. 4 (2013) 1700-1707. doi:10.1039/c2py20966g.

[41] T. Ogoshi, T. Fujiwara, M. Bertolucci, G. Galli, E. Chiellini, Y. Chujo, K.J. Wynne, Tapping mode AFM evidence for an amorphous reticular phase in a condensationcured hybrid elastomer: $\alpha, \omega$ dihydroxypoly(dimethylsiloxane)/poly(diethoxysiloxane)/fumed silica nanoparticles, J. Am. Chem. Soc. 126 (2004) 12284-12285. doi:10.1021/ja0474345. 